\title{
Discussions of Life Expectancy Moderate Relationships between Prognosis and Anxiety or Depression in Men with Advanced Cancer
}

\author{
Larry D. Cripe, M.D., ${ }^{1,2}$ Susan M. Rawl, Ph.D., R.N., ${ }^{1,4}$ Karen K. Schmidt, M.S.N.., Yan Tong, Ph.D., M.S., ${ }^{3}$ \\ Patrick O. Monahan, Ph.D., ${ }^{1,3}$ and Kevin L. Rand, Ph.D. ${ }^{1,5}$
}

\begin{abstract}
Purpose: Oncologists avoid prognostic discussions due to concerns about increasing patients' anxiety or depression. We sought to determine if perceived prognosis or extent of prognostic discussions predicted anxiety or depression and whether prognostic discussions moderated the relationship between prognosis and anxiety or depression.

Methods: Men with advanced cancer and their oncologists estimated the likelihood of survival at 6 months and reported extent of prognostic discussions. Anxiety and depression were measured by the Hospital Anxiety and Depression Scale (HADS).

Results: Men who died within 6 months reported higher scores on depression but not anxiety. Men who estimated a lower $(10 \%-75 \%)$ likelihood of surviving at least 6 months were more depressed and anxious than men who estimated a higher $(>90 \%)$ likelihood of survival. A similar relationship was seen with oncologists' prognostications. Men who reported having had full prognostic discussions with their oncologist had less depression compared with men who reported having had brief or no discussions. Men for whom the oncologists reported a full discussion had greater anxiety. The relationships between patient-perceived prognosis and depression or anxiety were moderated by extent of prognostic discussions as reported by the patient or oncologist, respectively.

Conclusion: Full prognostic discussions are associated with less depression among men who perceive a poor prognosis. Anxiety is increased in men if the oncologists report a full discussion. Oncologists should engage in prognostic discussions but assess for increased anxiety to facilitate coping with advanced cancer.
\end{abstract}

\section{Introduction}

O NCOLOGISTS FREQUENTLY AVOID explicit discussions of life expectancy or alternatives to chemotherapy, ${ }^{1-3}$ are reluctant to discuss hospice and resuscitation preferences, ${ }^{4}$ and make more optimistic rather than pessimistic statements in consultations. ${ }^{5}$ Patients with advanced cancer may consequently choose to receive aggressive treatment near the end of life rather than palliative care due to overly optimistic perceptions of life expectancy or the benefit of aggressive treatment. ${ }^{6-7}$ One explanation for incomplete prognostic discussions between patients and oncologists is oncologists' concerns that such discussions may increase anxiety or depression in patients with advanced cancer. These concerns seem reasonable given the prevalence of anxiety or depression in people with cancer ${ }^{8-10}$ and the correlation with disease stage in some ${ }^{11-13}$ but not all studies. ${ }^{14-15}$ However, the majority of patients with advanced cancer express clear preferences for honest prognostic disclosure. ${ }^{16}$ Furthermore, people with advanced cancer who discussed preferences for endof-life care with their oncologists were more likely to receive less aggressive medical care and have improved quality of life. ${ }^{17-18}$

Given the importance of prognostic disclosure to shared decision making, there is a critical need to better understand the relationships between prognostic discussions, perception of prognosis, and anxiety or depression. Thus, we asked two research questions in a cross-sectional study of men with

\footnotetext{
${ }^{1}$ Indiana University Simon Cancer Center, ${ }^{2}$ Division of Hematology and Oncology and ${ }^{3}$ Division of Biostatistics, Department of Medicine, Indiana University School of Medicine, ${ }^{4}$ Indiana University School of Nursing, and ${ }^{5}$ Department of Psychology, School of Science, Indiana University-Purdue University Indianapolis, Indianapolis, Indiana.

Accepted September 13, 2011.
} 
advanced cancer: (1) are patient anxiety and depression related to actual survival, patients' perceptions of prognosis, oncologists' perceptions of prognosis, or extent of prognostic discussions?; and (2) does patient- or oncologist-reported extent of prognostic discussion moderate the relationship between patients perceptions of prognosis and anxiety or depression? We were specifically interested in men because gender influences psychological responses to illness. ${ }^{19-21}$

\section{Methods}

\section{Study sample and procedures}

All study procedures were approved by the institutional review board. Patients with metastatic cancers for which there was no curative therapy and who were treated at Indiana University Simon Cancer Center by one of four collaborating medical oncologists between January and December 2008 were approached in the clinic. Eligibility criteria included: (1) men greater than 18 years of age; (2) at least one prior visit with the oncologist; (3) a life expectancy of greater than 3 months; and (4) ability to provide informed consent in English. Consented patients were given a study folder containing the survey and a self-addressed, stamped envelope. Patients who returned surveys were given a $\$ 25$ gift card. The treating oncologists completed surveys after the encounter.

Outcome variables. Anxiety and depression were measured by the Hospital Anxiety and Depression Scale (HADS). The HADS is a 14-item scale that consists of two 7item subscales. 22
Predictor variables. Demographic and disease-related variables: Patients provided information about age, education, income, race, ethnicity, marital status, employment status, living arrangements, and health insurance. The project manager abstracted the type of cancer, whether or not the patient was currently receiving chemotherapy, and the current status of disease (remission, stable, or progressive) from the medical record.

Overall survival (OS) from study enrollment: The OS from the date of study enrollment was calculated using information available through June 2010.

Patient and oncologist perceptions of prognosis: Patients and their oncologists estimated the likelihood of the patient being alive in 6 months given the current plan of care, by selecting one of the following response categories: greater than $90 \%$, about $75 \%$, about $50 \%$, about $25 \%$, less than $10 \%$, or don't know. Due to small number of responses in the categories other than "greater than $90 \%$," especially for patients, we dichotomized perceived prognosis into greater than $90 \%$ and $75 \%$ or less for subsequent bivariate and regression analyses (Table 1). This is consistent with the analysis of Weeks and colleagues. ${ }^{7}$

Extent of prognostic discussions: Patients were asked to indicate the extent of discussions about life expectancy by choosing one of the following statements: (1) We have not discussed my life expectancy because I do not want to discuss the information; (2) We have not discussed my life expectancy because my medical oncologist has not offered to have the discussion; (3) We have briefly discussed my life expectancy; and (4) We have discussed my life expectancy and I feel fully informed about what I might expect. No patient selected

Table 1. Associations between Depression or AnXiety Scores and Survival or Prognosis

\begin{tabular}{|c|c|c|c|c|c|c|c|c|c|}
\hline & \multicolumn{9}{|c|}{ HADS Subscale } \\
\hline & \multirow[b]{2}{*}{$n$} & \multicolumn{4}{|c|}{ Depression } & \multicolumn{4}{|c|}{ Anxiety } \\
\hline & & Mean & $S D$ & $\mathrm{P}^{*}$ & $E S$ & Mean & $S D$ & $\mathrm{P}^{*}$ & $E S$ \\
\hline \multicolumn{10}{|c|}{ Survival past 6 months } \\
\hline Yes & 67 & 3.8 & 3.0 & 0.019 & -0.66 & 5.5 & 3.8 & 0.463 & NA \\
\hline No & 15 & 5.9 & 3.9 & & & 6.3 & 3.6 & & \\
\hline \multicolumn{10}{|c|}{ Patient survival estimate, 6 months } \\
\hline $75 \%$ or less $(1)$ & 15 & 6.1 & 3.6 & 0.028 & 0.75 & 7.9 & 4.2 & 0.021 & 0.83 \\
\hline $90 \%$ or greater $(2)$ & 54 & 3.7 & 3.2 & $(1)>(2)$ & 0.88 & 4.9 & 3.5 & $(1)>(2)$ & \\
\hline Don't know (3) & 16 & 3.3 & 2.7 & $(1)>(3)$ & & 5.5 & 3.7 & & \\
\hline \multicolumn{10}{|c|}{ Oncologist survival estimate, 6 months } \\
\hline $75 \%$ or less & 55 & 4.7 & 3.4 & 0.027 & 0.53 & 6.2 & 3.9 & 0.023 & 0.51 \\
\hline $90 \%$ or greater & 30 & 3.0 & 2.7 & & & 4.3 & 3.3 & & \\
\hline Don't know & 0 & - & - & & & - & - & & \\
\hline \multicolumn{10}{|c|}{ Patient-reported extent of prognostic discussion } \\
\hline None (1) & 22 & 4.5 & 3.3 & 0.050 & 0.56 & 6.6 & 3.3 & 0.318 & NA \\
\hline Brief (2) & 35 & 4.7 & 3.6 & & & 5.1 & 4.0 & & \\
\hline Full (3) & 27 & 2.8 & 2.4 & & & 5.3 & 3.6 & & \\
\hline \multicolumn{10}{|c|}{ Oncologist-reported extent of prognostic discussion } \\
\hline None & 9 & 5.8 & 3.5 & 0.240 & NA & 5.3 & 3.8 & 0.967 & NA \\
\hline Brief & 41 & 4.0 & 3.4 & & & 5.6 & 3.4 & & \\
\hline Full & 35 & 3.7 & 3.0 & & & 5.5 & 4.2 & & \\
\hline
\end{tabular}

${ }^{*} P=p$ value from the $t$ test for two independent groups, and from ANOVA omnibus $F$ test for three independent groups. For variables with three groups, the group number $(1,2$, and 3$)$ is reported in parentheses, and if the omnibus test was significant ( $p<0.05)$ then post hoc comparisons between the pairs of the groups were tested and any significant pair-wise comparisons $(p<0.05)$ are shown using the group numbers [e.g., (1)> (2)]. ES denotes effect size. The effect size was determined with the use of Cohen's d statistic; an effect size of 0.20 is small, 0.50 moderate, and 0.80 large. SD denotes standard deviation. 
statement 1 , so there were three response categories. The wording of the oncologists' survey was complementary.

\section{Statistical analyses}

We summarized patient demographics and disease-related variables. Data were examined to ensure that normality and constant variance assumptions were appropriate. For Research Question 1, associations between categorical predictors and outcomes of anxiety and depression were tested with independent samples $t$ tests for binary predictors and analysis of variances (ANOVAs) for predictors with three categories. Family-wise Type I error was controlled by adjusting alpha for multiple comparisons. Specifically, significant omnibus tests for ANOVAs were followed up with post hoc pair-wise tests using the protected version of Fisher's Least Significant Difference. Linear regression models were then used to examine the unique associations between the main predictors of interest (perceived prognosis and extent of discussion) and outcomes while controlling for potentially confounding covariates.

For Research Question 2, moderation effects were assessed by using linear regression models to examine interaction terms between perceived prognosis variables and perceived prognostic discussion variables. A significant interaction was followed by analysis of "simple effects" by estimating separate models for each category of extent of discussion. Interaction tests were adjusted for multiple comparisons. Specifically, omnibus tests were adjusted using the false discovery rate method, and subsequent pair-wise tests from the "simple effect" analyses were further adjusted using the protected version of Fisher's Least Significant Difference.

To understand the magnitude of effects, Cohen's d effect size was computed for Research Questions 1 and 2 as the difference between two groups on their unadjusted (bivariate analyses) or adjusted (regression analyses) outcome means, divided by the pooled standard deviation. ${ }^{23}$

\section{Results}

Of the 114 men approached, 113 (99\%) consented to participate and 86 men (76\%) returned completed surveys; their characteristics are summarized in Table 2 . The median age was 60.4 years (range $23.8-81.3$ years). The most common cancers were gastrointestinal (34.9\%) or sarcomas (25.6\%). At the time of enrollment, $53(61.6 \%)$ men were receiving chemotherapy. Sixty-four $(74.4 \%)$ had stable disease; the remainder had progressive disease. The median OS was 11.9 months (Fig. 1). There were no differences in age, OS, or diagnoses between the men who completed the survey and the 27 men who did not.

Depression and anxiety scores are summarized in Table 2.The mean (standard deviation) scores for the depression and anxiety subscales were 4.1 (3.2) and 5.5 (3.8), respectively. Fourteen men $(16 \%)$ scored greater than 7 on the depression subscale and $24(28 \%)$ men scored greater than 7 on the anxiety subscale suggesting a depressive or anxiety state.

\section{Research Question 1: Are patient anxiety or depression related to actual survival, patient- or oncologist-perceived prognosis, or reported extent of prognostic discussions?}

There were no significant correlations between demographic and disease-related variables including type of cancer
Table 2. Patient $(N=86)$ Demographics, Disease and Treatment Status, Survival, and HADS Scores

\begin{tabular}{|c|c|c|}
\hline Characteristic & No. of patients & $\%$ \\
\hline \multicolumn{3}{|l|}{ Demographic } \\
\hline Age, years, median & \multicolumn{2}{|l|}{60.4} \\
\hline Range & \multicolumn{2}{|l|}{$24-81$} \\
\hline \multicolumn{3}{|l|}{ Race } \\
\hline White & 76 & 90.5 \\
\hline Black & 6 & 7.1 \\
\hline Hispanic or Latino & 2 & 2.4 \\
\hline \multicolumn{3}{|l|}{ Marital status } \\
\hline Married or partnered & 68 & 80 \\
\hline Other & 17 & 20 \\
\hline \multicolumn{3}{|l|}{ Living situation } \\
\hline Alone & 8 & 9.4 \\
\hline With other people & 77 & 90.6 \\
\hline \multicolumn{3}{|l|}{ Income } \\
\hline$\leq \$ 50,000$ per year & 32 & 40.5 \\
\hline$>\$ 50,000$ per year & 47 & 59.5 \\
\hline \multicolumn{3}{|l|}{ Education } \\
\hline High school degree or less & 27 & 31.8 \\
\hline Some college & 21 & 24.7 \\
\hline College graduate & 15 & 17.7 \\
\hline $\begin{array}{l}\text { Some graduate or } \\
\text { professional school or more }\end{array}$ & 22 & 25.9 \\
\hline \multicolumn{3}{|l|}{ Primary cancer } \\
\hline Gastrointestinal & 23 & 34.9 \\
\hline Genitourinary & 19 & 22.1 \\
\hline Thoracic & 14 & 16.3 \\
\hline Sarcoma & 22 & 25.6 \\
\hline Thymoma & 8 & 9.3 \\
\hline \multicolumn{3}{|l|}{ Disease status } \\
\hline Stable & 64 & 74.4 \\
\hline Progressive & 21 & 24.4 \\
\hline \multicolumn{3}{|l|}{ Treatment status } \\
\hline Receiving chemotherapy & 53 & 61.6 \\
\hline Not receiving chemotherapy & 32 & 37.2 \\
\hline \multicolumn{3}{|l|}{ Survival } \\
\hline Dead at $\leq 6$ months & 15 & 18.3 \\
\hline Dead at $\leq 12$ months & 35 & 42.7 \\
\hline Median overall survival, ( IQR) & $11.9(7.1-17.7 \mathrm{~m}$ & onths) \\
\hline \multicolumn{3}{|c|}{ Hospital Anxiety and Depression Scale (HADS) } \\
\hline $\begin{array}{l}\text { Depression subscale } \\
\text { (mean } \pm \text { std. deviation) }\end{array}$ & $4.1 \pm 3.2$ & \\
\hline $\begin{array}{l}\text { Anxiety subscale } \\
\quad(\text { mean } \pm \text { std. deviation })\end{array}$ & $5.5 \pm 3.8$ & \\
\hline
\end{tabular}

IQR, interquartile range.

listed in Table 2 or enrolling medical oncologist and anxiety or depression (data not shown). The results for other variables are summarized in 12 along with calculated effect sizes that range from 0.51 to 0.86 , which are moderate to large. ${ }^{23}$ In addition, it has been proposed that 0.36 or greater is a clinically meaningful effect size for psychological interventions on anxiety or depression in people with cancer. ${ }^{24}$ Men who died within 6 months of enrollment reported more symptoms of depression than men who were still alive $(p=0.019)$. No difference was observed for anxiety.

As summarized in Table 1, the majority (63\%) of men perceived a $90 \%$ or greater likelihood of surviving past 6 


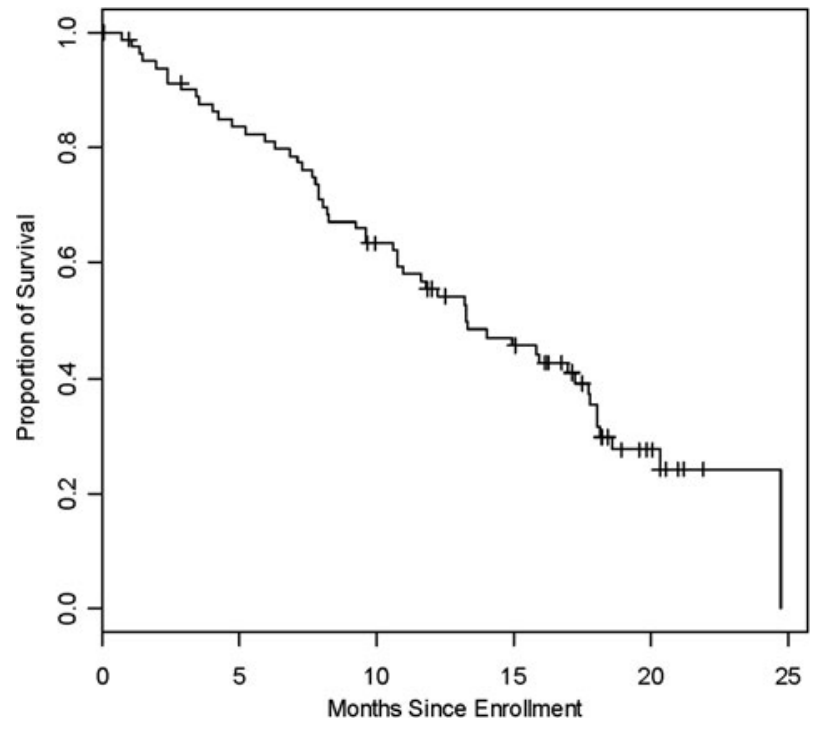

FIG. 1. Overall survival from study enrollment.

months; 16 (18\%) responded they "don't know." Fifteen patients $(17 \%)$ who perceived a lower likelihood of survival (75\% or less) at 6 months experienced more depression and anxiety (omnibus $p=0.028$ and 0.021 , respectively). Pair-wise comparisons showed that men who perceived a lower likelihood of surviving past 6 months had more depressive symptoms than those who reported higher $(90 \%$ or greater) likelihood of survival $(p<0.05)$. In addition, men who perceived a lower likelihood of survival had higher depression scores than those who reported they "don't know." Pair-wise comparisons demonstrated that the mean anxiety score was significantly higher for men who perceived a lower likelihood of survival beyond 6 months. Similarly, mean depression and anxiety scores were higher for men whose oncologists reported a lower likelihood of survival at 6 months.

Twenty-two men (26\%) reported having had no prognostic discussions with their oncologists. The extent of prognostic discussion was inversely associated with increased levels of depression (omnibus $p=0.050$ ). Pair-wise comparisons demonstrated a marginally significant difference between brief and full discussions $(p=0.054)$. In an exploratory analysis, we compared brief or no discussion with full discussions; men who reported having had a full discussion had significantly lower depressive symptoms ( $p=0.015$; effect size $[\mathrm{ES}]=0.56$ ). There was no association between anxiety and patientperceived extent of prognostic discussions. In addition, oncologist-reported extent of discussion was not associated with levels of depression or anxiety.

Linear regression was used to assess the relationships between perceived prognosis, reported extent of prognostic discussions, and anxiety or depression, controlling for the potentially confounding effects of age and whether or not the patient survived past 6 months. Age was controlled for because of its relevance to patient-physician communication and treatment preferences. Survival was controlled for because of the possible relationships between anxiety or depression as life is ending. Regression results demonstrated three findings. First, the bivariate relationships remained significant for prognosis and extent of discussion, after adjusting for age and survival. Second, both patient-perceived prognosis and patient-perceived extent of discussion were unique predictors of depression after adjusting for each other, and for age and survival. Third, the two patient-perceived prognostic pair-wise comparisons, which were not quite significant in the bivariate analyses, were significant in the models. Specifically, the mean depression score was significantly higher among men who reported having no discussion with their oncologist (versus full, $p=0.028$ ) or only a brief discussion (versus full, $p=0.020$ ). Those who perceived they had a worse prognosis had significantly higher depression than those who perceived a better prognosis, after adjusting for patient-perceived prognosis, age, and survival (75\% or less versus $>90 \%, p=0.036$ ).

\section{Research Question 2: Does patient- or oncologist- reported extent of prognostic discussion moderate the relationship between patient-perceived prognosis and anxiety or depression?}

We were specifically interested in whether the relationship between perceived prognosis and anxiety or depression was dependent on the extent of prognostic discussions. Because bivariate analyses showed a significant difference on depression scores between men who reported full discussions versus no or brief discussions, and because the oncologistperceived "no discussion" category was sparse, we examined a two-level variable (no or brief versus full), in addition to the three-level variable (none, brief, full). Both of these variables were used when examining interactions between patient perceptions of prognosis and patient- or oncologist-reported extent of prognostic discussions. A total of eight interactions were tested (three-level/two-level discussion crossed with patient/MD discussion crossed with anxiety/depression). Two significant interactions were found after adjusting for multiple comparisons (Table 3). The first interaction was observed between depression and patients' estimated likelihood of survival at 6 months and their reported extent of prognostic discussion. Among patients who reported a brief or no discussion, those who perceived a worse prognosis had higher depressive symptoms (omnibus $p=0.011$ ). Conversely, among patients who reported having had a full discussion about prognosis, there was no difference in depression by perceived prognosis. The second interaction involved patients' anxiety levels, their perceived prognosis, and oncologistreported extent of prognostic discussion. The mean anxiety score was greater for patients who reported a lower likelihood of survival beyond 6 months if the oncologist reported having had a full discussion (omnibus $p=0.002$ ). There was no difference in mean anxiety scores for patients whose oncologists reported having had no or only brief discussions.

\section{Discussion}

Men with advanced cancer who survived less than 6 months and those who perceived a lower likelihood of survival beyond the next 6 months reported more depressive symptoms and greater anxiety, compared with men who survived more than 6 months or who were more optimistic about their prognosis. However, men who reported having had a full prognostic discussion with their oncologist had less depressive symptoms than men who reported having had no or only brief prognostic discussions. The moderation analyses demonstrated that among patients with poor perceived 
Table 3. Interactions between Prognostic Discussions, Perceived Prognosis, and Depression or Anxiety

Interaction between patient-reported prognostic discussions and patient-perceived prognosis at 6 months on depression

\begin{tabular}{|c|c|c|c|c|c|}
\hline & \multirow[b]{2}{*}{$\mathrm{N}$} & \multicolumn{3}{|c|}{ Depression } & \multirow[b]{2}{*}{$E S$} \\
\hline & & Mean & $S D$ & $\mathrm{P}^{*}$ & \\
\hline \multicolumn{6}{|l|}{ Full discussion } \\
\hline \multicolumn{6}{|l|}{ Patient-perceived prognosis, 6 months } \\
\hline$>90 \%(1)$ & 18 & 2.3 & 1.9 & 0.188 & \\
\hline "<10\%" through "about 75\%" (2) & 3 & 2.7 & 2.9 & & \\
\hline Don't know (3) & 6 & 4.3 & 3.1 & & \\
\hline \multicolumn{6}{|l|}{ None or brief discussion } \\
\hline \multicolumn{6}{|l|}{ Patient-perceived prognosis, 6 months } \\
\hline$>90 \%(1)$ & 35 & 4.4 & 3.4 & 0.011 & 0.74 \\
\hline "<10\%" through "about $75 \% "(2)$ & 12 & 6.9 & 3.3 & $(2)>(1)$ & 3.23 \\
\hline Don't know (3) & 10 & 2.7 & 2.5 & $(2)>(3)$ & \\
\hline \multicolumn{6}{|c|}{ Interaction between oncologist-reported prognostic discussion and patient-perceived prognosis at 6 months on anxiety } \\
\hline & & \multicolumn{3}{|c|}{ Anxiety } & \\
\hline & $\mathrm{N}$ & Mean & $S D$ & $\mathrm{P}^{*}$ & \\
\hline \multicolumn{6}{|l|}{ Full discussion } \\
\hline \multicolumn{6}{|l|}{ Patient-perceived prognosis, 6 months } \\
\hline$>90 \%(1)$ & 20 & 3.6 & 3.2 & 0.002 & 1.81 \\
\hline "<10\%" through "about $75 \% "(2)$ & 7 & 9.4 & 3.5 & $(2)>(1)$ & \\
\hline Don't know (3) & 8 & 6.6 & 4.7 & & \\
\hline \multicolumn{6}{|l|}{ None or brief discussion } \\
\hline \multicolumn{6}{|l|}{ Patient-perceived prognosis, 6 months } \\
\hline$>90 \%(1)$ & 33 & 5.6 & 3.5 & 0.444 & \\
\hline "<10\%" through "about $75 \% "(2)$ & 8 & 6.6 & 4.6 & & \\
\hline Don't know (3) & 8 & 4.4 & 2.1 & & \\
\hline
\end{tabular}

ES denotes effect size. The effect size was determined with the use of Cohen's d statistic; an effect size of 0.20 is small, 0.50 moderate, and 0.80 large. SD denotes standard deviation.

Values in bold are significant at $p<.05$

prognosis, having had a full prognostic discussion was associated with less depression. Thus, prognostic discussions may offer provide opportunities to ameliorate symptoms of depression for men with advanced cancer.

The moderation analysis also demonstrated that men who perceived a lower likelihood of survival at 6 months experienced increased anxiety if the oncologist reported having had a full discussion about prognosis. This is consistent with prior observations that the manner in which the oncologist conducts consultations correlate with patients' levels of anxiety. $^{2,25-26}$ Of particular relevance is a study of initial consultations between patients with advanced cancer and their oncologists. Disclosure of prognostic information was not predictive of anxiety immediately following the consultation. However, oncologists' encouragement of patient participation in treatment decision making was correlated with increased anxiety levels that persisted for at least 2 weeks. ${ }^{2}$ This raises the possibility that anxiety may result when oncologists' communications are not congruent with patient preferences for decision making. In the current study, increased anxiety levels could have resulted from oncologists providing information based on their own preferences rather than those of the patient. This interpretation is supported by results from a recent study that showed that patients with advanced cancer who were anxious were also less comfortable asking questions. ${ }^{26}$
There are several potential limitations of this study. First, the study was cross-sectional and causation cannot be inferred. It is possible that men who were depressed or anxious reported a more pessimistic prognosis as an expression of their psychological state rather than the prognosis leading to depressive symptoms or anxiety. In support of this conjecture, Schofield reported that preferences for discussions of life expectancy were correlated with increased symptoms of depression as measured by the HADS. ${ }^{27}$ However, in this study, relationships between patient-reported or oncologistreported extent of prognostic discussions and patients' or oncologists' perceptions of life expectancy or actual 6-month survival were not significant (data not shown). Furthermore, the moderation of depression scores by patient-reported extent of prognostic discussions strongly suggests that perceived prognosis led to anxiety or depression. It is difficult to imagine how a prognostic discussion would improve depressive symptoms if the patients' perceptions of a poor prognosis led to depression.

Second, we relied upon patient- or oncologist-recall and our study was not designed to independently verify the accuracy of the reported extent of prognostic discussions. However, we specifically phrased the survey question to encompass both life expectancy and discussions about what a person with advanced-stage cancer may experience in the future to capture a broader range of prognostic discussions. Results of the 
prospective Coping with Cancer Study demonstrated that patients who reported they had discussed their wishes for end-oflife care with their physicians received less aggressive medical care, earlier hospice referral, and improved quality of life. ${ }^{17-18}$ Therefore, we conclude that patient self-report of prognostic discussions seem to accurately reflect their experiences.

Third, the observed survival of participants after enrollment was better than expected. However, the relatively favorable prognosis of these men may have weakened the relationships between depression or anxiety and prognostic discussions. Oncologists tend to delay discussions of prognosis until there are no further treatments. ${ }^{4}$ Thus, the relationship between oncologist-reported prognostic discussions and anxiety might have been stronger if participants were closer to death. Fourth, the results may only apply to Caucasian men due to the low number of other races. Finally, we did not assess for physical symptoms, which may have contributed to depression, ${ }^{28-29}$ although a relationship between physical symptoms and anxiety or depression is not uniformly observed. ${ }^{30}$

There are several strengths of this study. First, we recruited men with advanced cancer who were still receiving care directed by a medical oncologist. Thus, prognostic discussions remained highly relevant for treatment decision making for the enrolled cohort. Studies of patients enrolled on palliative care or hospice likely reflect a group of people who have accepted their prognosis and decided against further chemotherapy. ${ }^{9,31}$ Second, there was a high rate of enrollment and completion of surveys. Third, frequency of probable or definite anxiety disorder or depression was in the range reported in larger studies of patients with cancer. ${ }^{32,33}$ Fourth, as anticipated, the patients were quite optimistic about their life expectancy. This finding is consistent with the observation that most individuals tend to be overly optimistic across multiple domains. ${ }^{34}$ Further empiric research is required to determine the extent to which patient personality (e.g., trait hope or optimism) accounts for the observed variance in prognostic estimates. Thus, our results are likely applicable to other men with advanced cancer.

In conclusion, the findings of this study enrich our understanding of the complicated relationships among anxiety or depression, perceived prognosis, and prognostic discussions among men with advanced cancer. Depressive symptoms were lower in men who perceived a poor prognosis and reported having had a full prognostic discussion with their oncologist. We also observed higher levels of anxiety when oncologists reported having had a full prognostic discussion. These results demonstrate the need to differentiate anxiety and depression. Anxiety stems from perception of a possible, though uncertain, threat; depression stems from perception of past or unavoidable future loss. ${ }^{35}$ An implication of this distinction is that, although both anxiety and depression are unpleasant, anxiety may serve as a useful cue for oncologists, indicating the need to clarify patient preferences for information and decision making as a means to facilitate positive adjustment. ${ }^{36}$ These results strongly suggest that prognostic discussions are more helpful, than harmful, to men with advanced cancer.

\section{Acknowledgments}

Presented in part at the 44th annual meeting of the American Society of Clinical Oncology, May30-June 3, Chicago,
Illinois, and the International Psycho-Oncology Society's 11th World Congress of Psycho-Oncology, Vienna, Austria, June 21-29, 2009.

\section{Author Disclosure Statement}

Supported by the Paul Ogle Foundation, Inc., Jeffersonville, Indiana. No competing financial interests exist.

\section{References}

1. Audrey S, Abel J, Blazeby JM, Falk S, Campbell R: What oncologists tell patients about survival benefits of palliative chemotherapy and implications for informed consent: Qualitative study. BMJ 2008;337:a752.

2. Gattellari M, Voigt KJ, Butow PN, Tattersall MH: When the treatment goal is not cure: Are cancer patients equipped to make informed decisions? J Clin Oncol 2002;20:503-513.

3. Koedoot CG, Oort FJ, de Haan RJ, Bakker PJ, de Graeff A, de Haes JC: The content and amount of information given by medical oncologists when telling patients with advanced cancer what their treatment options are: Palliative chemotherapy and watchful-waiting. Eur J Cancer 2004;40:225-235.

4. Huskamp HA, Keating NL, Malin JL, Zaslavsky AM, Weeks JC, Earle CC, Teno JM, Virnig BA, Kahn KL, He Y, Ayanian JZ: Discussions with physicians about hospice among patients with metastatic lung cancer. Arch Int Med 2009;169:954-962.

5. Robinson TM, Alexander SC, Hays M, Jeffreys AS, Olsen MK, Rodriguez KL, Pollak KI, Abernethy AP, Arnold R, Tulsky JA: Patient-oncologist communication in advanced cancer: predictors of patient perception of prognosis. Support Care Cancer 2008;16:1049-1057.

6. Craft PS, Burns CM, Smith WT, Broom DH: Knowledge of treatment intent among patients with advanced cancer: A longitudinal study. Eur J Cancer Care 2005;14:417-425.

7. Weeks JC, Cook EF, O'Day SJ, Peterson LM, Wenger N, Reding D, Harrell FE, Kussin P, Dawson NV, Connors AF Jr, Lynn J, Phillips RS: Relationship between cancer patients' predictions of prognosis and their treatment preferences. JAMA 1998;279:1709-1714.

8. Sellick SM, Edwardson AD: Screening new cancer patients for psychological distress using the hospital anxiety and depression scale. Psycho-Oncology 2007;16:534-542.

9. Wilson KG, Chochinov HM, Skirko MG, Allard P, Chary S, Gagnon PR, Macmillan K, De Luca M, O'Shea F, Kuhl D, Fainsinger RL, Clinch JJ: Depression and anxiety disorders in palliative cancer care. J Pain Symptom Manage 2007;33: 118-129.

10. Zabora J, BrintzenhofeSzoc K, Curbow B, Hooker C, Piantadosi S: The prevalence of psychological distress by cancer site. Psycho-Oncology 2001;10:19-28.

11. Andersen BL, Shapiro CL, Farrar WB, Crespin T, WellsDigregorio S: Psychological responses to cancer recurrence. Cancer 2005;104:1540-1547.

12. Barnett MM: Does it hurt to know the worst? Psychological morbidity, information preferences and understanding of prognosis in patients with advanced cancer. PsychoOncology. 2006;15:44-55.

13. Lo C, Zimmermann C, Rydall A, Walsh A, Jones JM, Moore MJ, Shepherd FA, Gagliese L, Rodin G: Longitudinal study of depressive symptoms in patients with metastatic gastrointestinal and lung cancer. J Clin Oncol 2010;28:3084-3089.

14. Bergquist H, Ruth M, Hammerlid E: Psychiatric morbidity among patients with cancer of the esophagus or the gastro- 
esophageal junction: A prospective, longitudinal evaluation. Dis Esophagus 2007;20:523-529.

15. Walker MS, Zona DM, Fisher EB: Depressive symptoms after lung cancer surgery: Their relation to coping style and social support. Psycho-Oncology. 2006;15:684-693.

16. Hagerty RG, Butow PN, Ellis PA, Lobb EA, Pendlebury S, Leighl N, Goldstein D, Lo SK, Tattersall MH: Cancer patient preferences for communication of prognosis in the metastatic setting. J Clin Oncol 2004;22:1721-1730.

17. Mack JW, Weeks JC, Wright AA, Block SD, Prigerson HG: End-of-life discussions, goal attainment, and distress at the end of life: Predictors and outcomes of receipt of care consistent with preferences. J Clin Oncol 2010;28:1203-1208.

18. Wright AA, Zhang B, Ray A, Mack JW, Trice E, Balboni T, Mitchell SL, Jackson VA, Block SD, Maciejewski PK, Prigerson HG: Associations between end-of-life discussions, patient mental health, medical care near death, and caregiver bereavement adjustment. JAMA 2008;300:1665-1673.

19. Keller M, Henrich G: Illness-related distress: Does it mean the same for men and women? Gender aspects in cancer patients' distress and adjustment. Acta Oncologica 1999;38: 747-755.

20. Kiss A, Meryn S: Effect of sex and gender on psychosocial aspects of prostate and breast cancer. BMJ 2001;323:10551058.

21. Walsh D, Zhukovsky DS, Walsh D, Zhukovsky DS: Communication in palliative medicine: A pilot study of a problem list to capture complex medical information. Am J Hospice Palliat Care 2004;21:365-371.

22. Singer S, Kuhnt S, Gotze H, Hauss J, Hinz A, Liebmann A, Krauss O, Lehmann A, Schwarz R: Hospital anxiety and depression scale cutoff scores for cancer patients in acute care. British Jnl of Cancer 2009;100:908-912.

23. Cohen J: Statistical Power Analysis for the Behavioral Sciences, 2nd ed. Hillsdale, NJ: Erlbaum Associates, 1988.

24. Sheard T, Maguire P: The effect of psychological interventions on anxiety and depression in cancer patients: Results of two meta-analyses. Br J Cancer 1999;80:1770-1780.

25. Dimoska A, Butow PN, Dent E, Arnold B, Brown RF, Tattersall MHN: An examination of the initial cancer consultation of medical and radiation oncologists using the Cancode interaction analysis system. Br J Cancer 2008;98:1508-1514.

26. Spencer R, Nilsson M, Wright A, Pirl W, Prigerson H: Anxiety disorders in advanced cancer patients: Correlates and predictors of end-of-life outcomes. Cancer 2010;116:1810-1819.
27. Schofield PE, Butow PN, Thompson JF, Tattersall MH, Beeney LJ, Dunn SM: Psychological responses of patients receiving a diagnosis of cancer. Ann Oncol 2003;14:48-56.

28. Delgado-Guay M, Parsons HA, Li Z, Palmer JL, Bruera E: Symptom distress in advanced cancer patients with anxiety and depression in the palliative care setting. Support Care Cancer 2009;17:573-579.

29. Lloyd-Williams M, Dennis M, Taylor F, Lloyd-Williams M, Dennis M, Taylor F: A prospective study to determine the association between physical symptoms and depression in patients with advanced cancer. Palliat Med 2004;18: 558-563.

30. Teunissen SCCM, de Graeff A, Voest EE, de Haes JCJM: Are anxiety and depressed mood related to physical symptom burden? A study in hospitalized advanced cancer patients. Palliat Med 2007;21:341-346.

31. Akechi T, Okuyama T, Sugawara Y, Nakano T, Shima Y, Uchitomi Y: Major depression, adjustment disorders, and post-traumatic stress disorder in terminally ill cancer patients: Associated and predictive factors. J Clin Oncol 2004;22:1957-1965.

32. Hotopf M, Chidgey J, Addington-Hall J, Ly KL: Depression in advanced disease: A systematic review. Part 1. Prevalence and case finding. Palliat Med 2002;16:81-97.

33. Ibbotson $\mathrm{T}$, Maguire $\mathrm{P}$, Selby $\mathrm{P}$, Priestman $\mathrm{T}$, Wallace L: Screening for anxiety and depression in cancer patients: The effects of disease and treatment. Eur J Cancer 1994; 30A:37-40.

34. Taylor SE, Collins RL, Skokan LA, Aspinwall LG: Maintaining positive illusions in the face of negative information: Getting the facts without letting them get to you. Journal of Social and Clinical Psychology 1989;8:114-129.

35. Epstein S: Anxiety, arousal, and the self-concept. Issues Ment Health Nurs 1985;7:265-305.

36. Mystakidou K, Parpa E, Tsilika E, Pathiaki M, Galanos A, Vlahos L: Traumatic distress and positive changes in advanced cancer patients. Am J Hosp Palliat Care 2007;24:270-276.

Address correspondence to: Larry D. Cripe, M.D. 535 Barnhill Drive Indianapolis, IN 46202

E-mail: lcripe@iupui.edu 